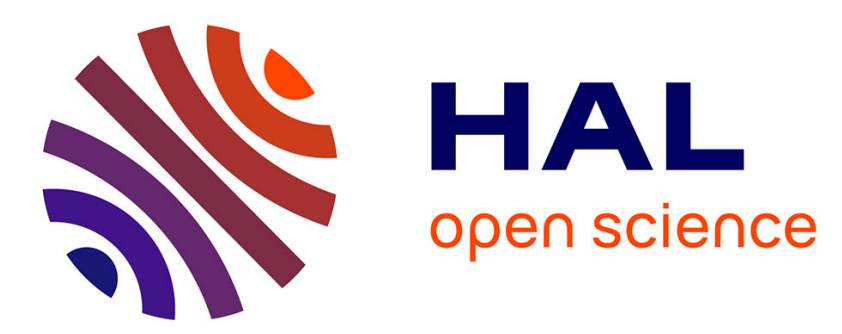

\title{
Modeling and underwater characterization of cymbal transducers and arrays
}

J. Zhang, Anne-Christine Hladky, W.J. Hughes, R. Newnham

\section{To cite this version:}

J. Zhang, Anne-Christine Hladky, W.J. Hughes, R. Newnham. Modeling and underwater characterization of cymbal transducers and arrays. IEEE Transactions on Ultrasonics, Ferroelectrics and Frequency Control, 2001, 48, pp.560-568. hal-00151690

\section{HAL Id: hal-00151690 \\ https://hal.science/hal-00151690}

Submitted on 28 Jul 2021

HAL is a multi-disciplinary open access archive for the deposit and dissemination of scientific research documents, whether they are published or not. The documents may come from teaching and research institutions in France or abroad, or from public or private research centers.
L'archive ouverte pluridisciplinaire HAL, est destinée au dépôt et à la diffusion de documents scientifiques de niveau recherche, publiés ou non, émanant des établissements d'enseignement et de recherche français ou étrangers, des laboratoires publics ou privés. 


\title{
Modeling and Underwater Characterization of Cymbal Transducers and Arrays
}

\author{
Jindong Zhang, Anne-Christine Hladky-Hennion, W. Jack Hughes, Member, IEEE, \\ and Robert E. Newnham, Member, IEEE
}

\begin{abstract}
The cymbal is a miniaturized class $\mathbf{V}$ flextensional transducer that was developed for potential use as a shallow water sound projector and receiver. Single elements are characterized by high $Q$, low efficiency, and medium power output capability. Its low cost and thin profle allow the transducer to be assembled into large flexible arrays. Efforts were made to model both single element and transducer arrays by coupling finjte element analysis (ATILA) and the integral equation formulation (EOI). The pressure and velocity distributions on the Burface elements were calculated by ATILA and later used with EQI to calculate the far field properties of the transducer eloment and arrays. It eliminates the mash of the fild domain and makes the 3-D model of a transducer possible. Three-dimensional models of a cymbal transducer and a $\$ \times 3 \mathrm{cymbal}$ array wore developed in the modeling. Vory good agreement was obtained betweon modeling and measurement for single olement transducers. By coupling finite clement analysis with the integral equation method using boundary elements, acoustic interaction effects wore taken into account. Reasonable agreement was obtained between calculation and mansurement for a $3 \times 3$ array.
\end{abstract}

\section{INTRODUCTION}

$T^{2}$ He CYMBAl transducers are minjaturized class $\mathrm{V}$ flexI tensional transducers. They consist of a piezoelectric disk (poled in the thickness direction) sandwiched between two "cymbal-shaped" metal end caps. The metal caps serve as a mechanical transformer that transform the high impedance, small extensional motion of the ceramic into low inpedance, large fexural notion of the shell. The cymbal originally was designed as an actuator, which provides a. sizable displacement as well as moderate generatjve force, bridging the gap between the two most common actuators, bimorph and the multilayer [1]. It was later proposed [2] as an underwater transducer for use as a sound projector and hydrophone. Because the cymbal transducer is small compared to the wavelength in water around resonance, it has modest radiation efficiency as a sound projector and a relatively high $Q$. It is necessary to assemble them into arrays to achieve the desired sonrce level and directivity. In

Manuscriph received Marci 17, 2000; accepted August 11, 2000. This work is fundod by the Office of Naval Research and by Advanced Research Projects Agency, Grant \#N00014-96-1-1173.

J. Zhang and R. E. Newnham are with the Materials Research Laboratory, The Pennsylvania State University, University Park, PA (e-mail; jxz1320psu edu).

A. C. Hladky-Hennion is with the IEMN-Departement I.S.E.N. 59046 Lille, France.

W. J. Hughtes is with the Applied Research Laboratory, 'I the Pennaylvania State University, University Park, PA. assembling arrays, it always is desirable to have the transducer elements close packed in the array to save space. When element-to-element spacing is much smaller than the acoustic wavelength, acoustic interactions occur that lead to different acoustic loading on each transducer element, depending on its position in the erray [3]. This then results in significant variations in the volume velocity of each array element. These interactions reduce the acoustic output power of the array and, in some extreme cases, a transducer element may have a negative radiation resistance and absorb acoustic power. However, the acoustic interaction leads to increased radiation resistance, therefore improving the radiation efficiency [4]. The acoustic loading effect is advantageous in the case of cymbal array because it improves the radiation efficiency.

The objective of this paper is to characterize the cymbal as an underwater transducer and attempt to model both single element and array by coupling finite-element analysis and the integral equation method.

\section{Finite Element Modeling of an UNDERWATER Transducer}

The finite-element method has been used extensively in modelint complex transducer structures for more than 20 years. Many FEA software packages are commercially available, including ANSYS [5], PZFLEX [6], and ATILA [7]. The ATILA is specially designed for underwater transducers, which take into account the coupling between the transducer mechanical structure and the surrounding medium. In modeling underwater transducers, two approaches usually are used.

In the first method, a finite fluid domain is modeled in addition to the mesh of the solid structure, which is adapted from the ATILA code. Kinematic and dynamic continuity conditions are imposed at the interface for displacement and pressure fields. To absorb various components of the radiated field, damper elements are applied on the external surface $\Gamma$ of the surrounding fluid domain [8]. The use of damper elements provides detailed information about the acoustic near field properties.

This method necessitates the modeling of the fluid domain, which in some cases leads to large meshes and is not well suited to 3-D modeling. A second method is to model only the solid structure using the finite element method, then couple it to an integral equation formulation to account for the acoustic radiation problems. In this way the 
size of the mesh and the computation time can be significantly reduced [9]. By coupling the finite element and integral equation (EQI) methods, transducer arrays can be modeled.

The EQI is based on the Helmholtz-Kirchhoff Integral Equation, which is expressed as [10]:

$$
\begin{aligned}
& \iint\left\{p\left(r^{\prime}\right) \frac{\partial G\left(r, r^{\prime}\right)}{\partial n^{\prime}}-\frac{\partial p\left(r^{\prime}\right)}{\partial n^{\prime}} G\left(r, r^{\prime}\right)\right\} d r^{\prime}= \\
& \begin{cases}\alpha(r) p(r) / 4 \pi & r \in \Gamma \\
p(r) & r \in \Omega_{f}\end{cases}
\end{aligned}
$$

where, $G\left(r^{\prime}, r^{\prime}\right)=\frac{1}{4 \pi} \frac{e^{i k\left|r-r^{\prime}\right|}}{\left|r-r^{\prime}\right|}$ is the Green function. $\Gamma$ is the external surface of the solid structure, $\Omega_{f}$ is the infinite fluid domain surrounding the solid structure, $r$ is a point outside $\Gamma, r^{\prime}$ is a point on $\Gamma$, and $\alpha(r)$ is the solid angle at the point $r$.

The discretization of the integral equation on $\Gamma \mathrm{con}$ sists of dividing the external surface of the structure into elements intercomected by nodes. On each element the pressure field and its normal derivative are connected to the nodal values by an interpolation function. Discretization leads to $\mathrm{N}$ equations with $\mathrm{N}$ unknowns, where $\mathrm{N}$ is the number of nodes in the grid. The matrix form of the system is:

$$
[A]\{p\}=[B]\left\{\frac{\partial p}{\partial n}\right\} .
$$

Matrices $[\mathrm{B}]$ and $[\mathrm{A}]$ come from the integration of the Green function, and their normal derivatives are computed by the interpolation functions. The vectors $\{p\}$ and $\{\partial p / \partial n\}$ contain the nodal pressures of the system and their nonnal derivatives. The displacement vector normal to the surface is given by:

$$
\frac{\partial p(r)}{\partial n}=\rho \dot{w}^{2} u_{n}(r)
$$

The solution of the linear systerns provides the pressures at the nodes of the surface, from which the pressure at any point in the fluid $\Omega_{f}$ can be calculated.

In our approach, the solid structure is first meshed with special surface elements. Through harmonic analysis, the displacement and pressure field of the solid structure and the surface elements can be computed as a function of frequency using the finite element code ATILA. Then by enforcing kinematic and dynamic continuity condilions at the interface, the far field and near field pressures in the fluid domain are calculated with EQI.

\section{Experimentai. Procedure}

\section{A. Fabrication of the Cymbal Transducer and Array}

The detailed fabricalion procedure of cymbal transducer and arrays was described in a previously published paper [11]. The piezoelectric ceramic disks (PKI402,
Piezokinetics Inc, Bellefonte, PA) have a thickness of $1 \mathrm{~mm}$ and a diameter of $12.7 \mathrm{~mm}$, and they were poled in the thickness direction. Titanium sheets of $0.25 \mathrm{~mm}$ thickness were used as the cap material. The shaped caps had a diameter of $12.7 \mathrm{~mm}$. The cavity diameter was $9.0 \mathrm{~mm}$ at. the bottom and $3.2 \mathrm{~mm}$ at the top. The cavity depth was $0.32 \mathrm{~mm}$. Two different epoxy systems were used in this study. One is a high bonding strength insulating epoxy (Emerson and Cuming, Billerica, MA). A ratio of three parts $45 \mathrm{LV}$ epoxy resin to one part $15 \mathrm{LV}$ hardener was used. The other one is an E-solder conductive epoxy (VonRoll ISOLA, New Haven, CT). In both cases, the thickness of the glue layer was approximately $40 \mu \mathrm{m}$. In the $3 \times 3$ array, the element center-to-center spacing was kept at $15 \mathrm{~mm}$

\section{B. Charucterization of the Cymbal and Arrays}

Underwater calibration tests of single cymbals were performed at the Applied Research Laboratory, Penn State. The tank measured $5.5 \mathrm{~m}$ in depth, $5.3 \mathrm{~m}$ in width and $7.9 \mathrm{~m}$ in length. A pure tone sinusoidal pulse signal of $2-$ ms duration was applied to the test transducer, and its acoustic output was monitored with a standard F33 hydrophone. The test transducer and the standard were positioned at a depth of $2.74 \mathrm{~m}$ and separated by a distance of $3.16 \mathrm{~m}$. The mechanical $Q$, transmitting voltage response (TVR), free-field voltage sensitivity (FFVS), and directivity pattern were evaluated.

In the underwater test, the cymbal transducer and array must be insulated from the conductive water in the tank. In addition, the array has to be rotated to observe the directivity pattern. A potting technique was devised for the transducer to maintain a mechanically free condition [11]. For single elements, a coaxial cable was first attached to the flange of the metal cap using silver epoxy. The cymbal and part of the cable then were potted in polyurethane with a thickness of about $0.5 \mathrm{~mm}$. The polyurethane layer insulated the cymbal from the conductive water in the water tank. The $3 \times 3$ array was fixed at the end of a long plastic tube to allow rotation. The electrical lead wires passed through the plastic tube and were connected to the measurement system at the other end of the tube. The diameter of the tube is small compared to the wavelength in water so it does not interfere with the acoustic field generated by the array. The potted cymbal transducer and array are shown in Fig. 1.

\section{Results And Discussion}

\section{A. Single Element}

Due to symmetry, only a quarter of the transducer structure was modeled. There are symmetry planes across $\mathrm{XOY}$ and XOZ. The mesh of the entire structure is too complicated to see any dotails; therefore, only the mesh of the surface elemeut of the cymbal transducer is shown 


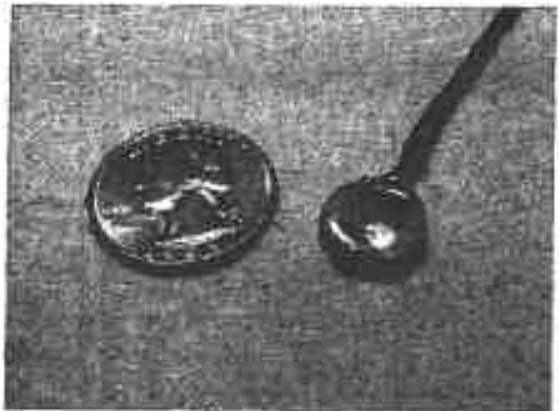

(a) single clement

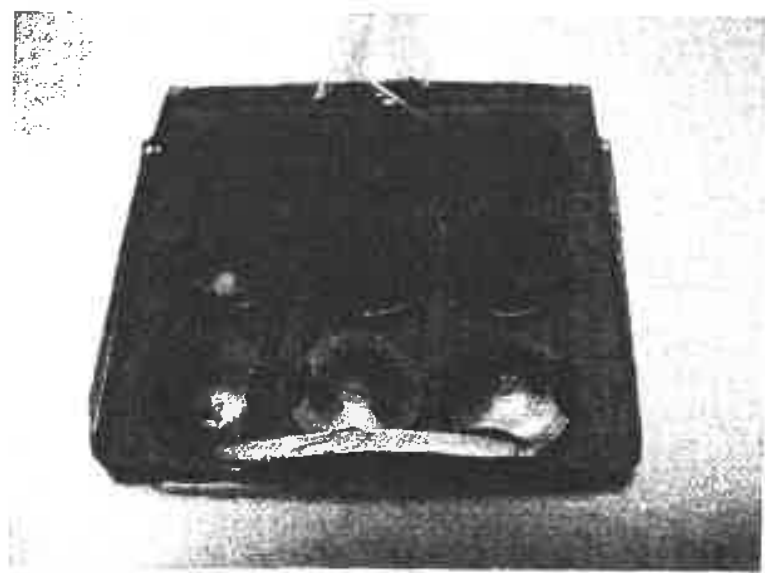

(b) $3 \times 3$ array

Fig. 1. Photograplus of a cymbal trunsducer and a $3 \times 3$ array potted in polyurethane.

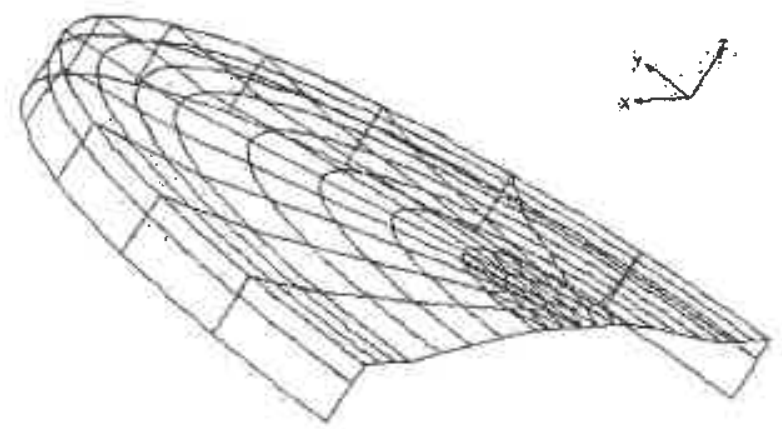

Fig. 2. Mesh of the surface elements of a single element.

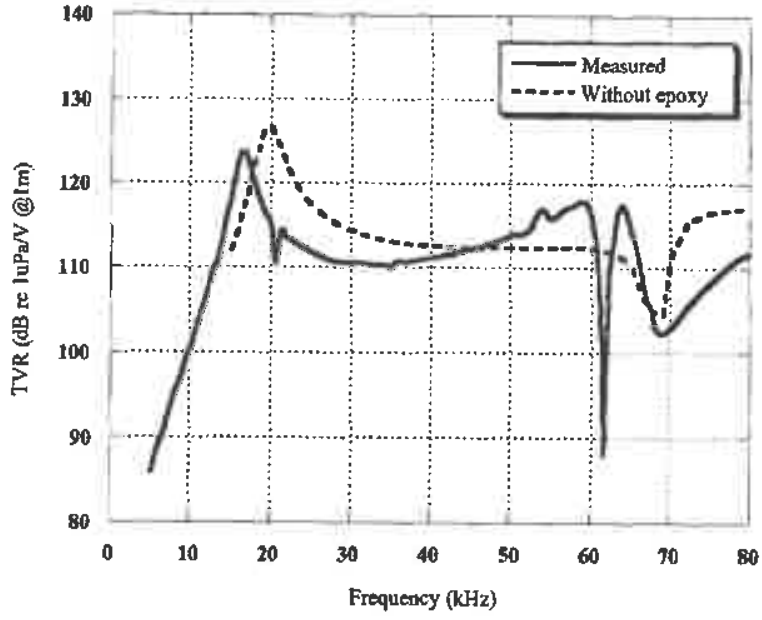

Fig. 3. Comparison of experimental and calculated TVR of a single element. Computation did not irclude the epoxy bonding layer.

in Fig. 2. The symmetry plane XOY is grounded and $1 \mathrm{~V}$ was applied to the upper side of the ceramic. Because $1 \mathrm{~V}$ was applied to a thickness of $0.5 \mathrm{mmm}$, which is half of the thickness of the ceramic, the electric field was actually $1 \mathrm{~V} / 0.5 \mathrm{mim}=2 \mathrm{~V} / \mathrm{mm}$. It is equivalent to an applied voltage of $2 \mathrm{~V}$ for a 1 min-thick ceramic. Therefore, what the program calculates is source level (SL). To obtain the TVR, the following equation was used:

$$
S L=T V R+20 \log V .
$$

Here $20 \log V=6$. Thus, we have to subtract $6 \mathrm{~dB}$ from the calculated source level to get TVR. For the same reason, the calculated impedance was multiplied by two to get TVR for a $1 \mathrm{~mm}$-thick ceramic disk.

Because the epoxy thickness is very small compared with the ceramic and the caps, we initially did not include the epoxy layer in the model, assuming it has little effect on the transducer performance. Fig. 3 shows the calculated TVR of a cymbal transducer compared with measurement. Without modeling the glue layer, the calculated resonance frequency was about $20 \mathrm{kHz}$ compared to the measured resonance frequency of $16.6 \mathrm{kHz}$. The considerable difference in resonance frequency suggests that the epoxy layer increases the eflective compliance of the cymbal structure substantially. Therefore, the epoxy layer must be included in the model even at the cost of a larger mesh and considerably increased computation time.

In the next step, the epoxy layer was included in the modeling. Its thickness was assumed to be $40 \mu \mathrm{m}$. The calculated TVR is shown in Fig. 4 and compared with the measured values. A nearly perfect match was obtained over a wide frequency range from $10 \mathrm{kHz}$ to $80 \mathrm{kHz}$. The four peaks at $20 \mathrm{kHz}, 34 \mathrm{kHz}, 53 \mathrm{kHz}$, and $62 \mathrm{kHz}$ come from the resonance of the air bubbles in the cured polyurethane and will be ignored in the discussion. The major peak at $17 \mathrm{kHz}$ in the TVR curve corresponds to the first flextertsional mode of the caps, which is illustrated in Fig. 5(a). 


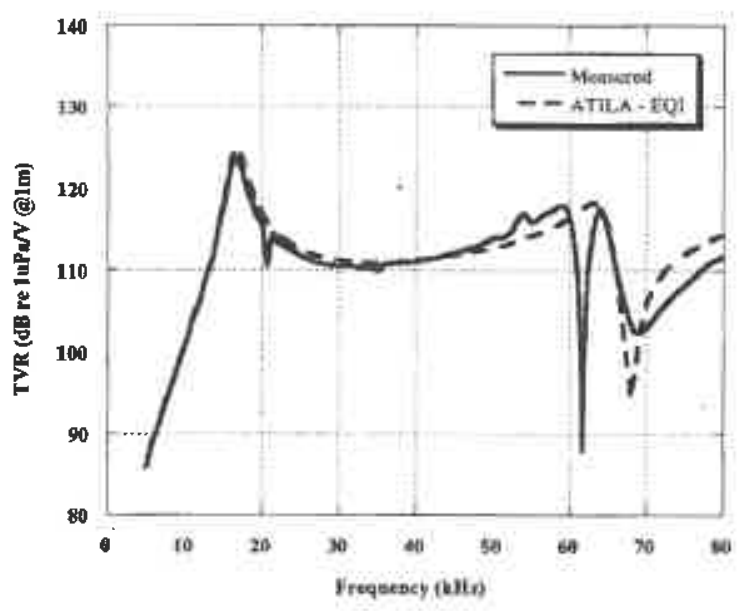

Fig. 4. Calculated and measured TVR of single cymbal modcled more accurately with the bonding layer.

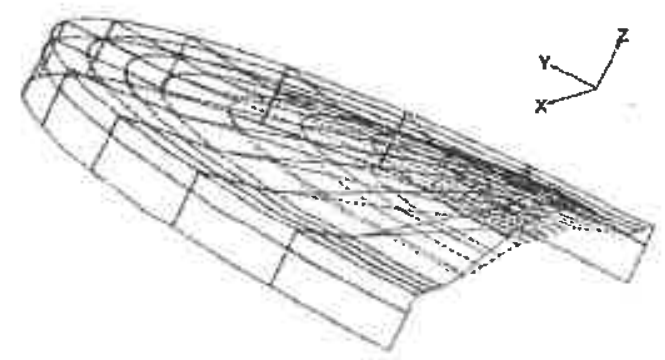

(a) $17 \mathrm{k} \mathrm{Hz}$

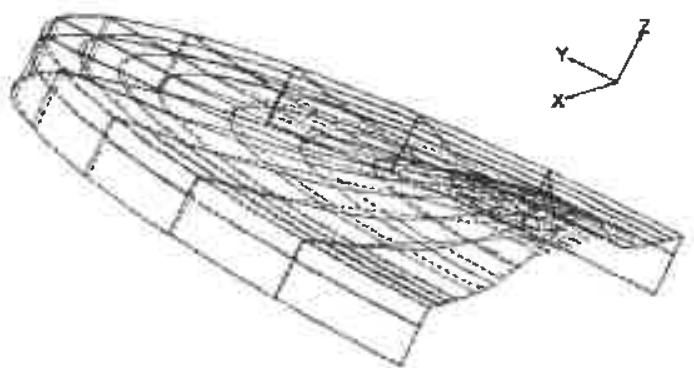

(b) $68 \mathrm{kHz}$

Fig. 5. Displaced shape of the cymbal transducer at frequency: (a) $17 \mathrm{kHz}$, (b) $68 \mathrm{kHz}$.

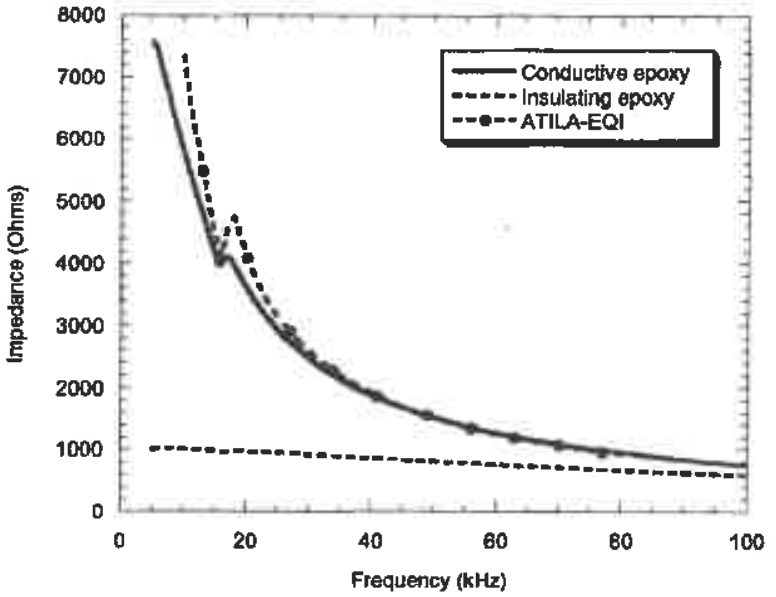

Fire. fi. The cakculated and measured inapertance of a rymbal trome durver:

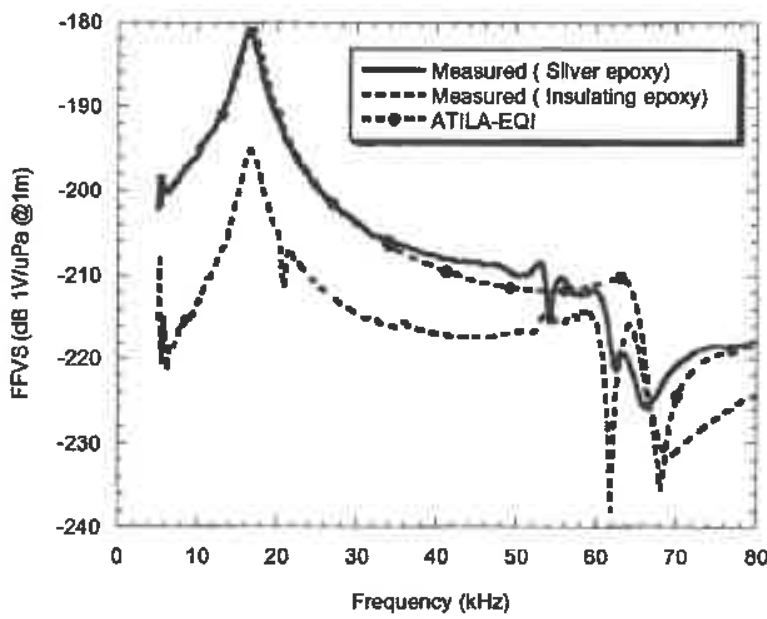

Fig. 7. Calculated FFVS of cymbal transducer based on reciprocity.

There is a sharp dip at about $68 \mathrm{kHz}$, which originates from the second flextensional mode of the metal caps. As secr from the vibration mode in Fig. $5(b)$ at this frequency, two portions of the cap vibrated out of phase. The pressures from different portions of the metal caps cancel out, leading to a sharp drop in transmit response.

The calculated impedance of a cymbal transducer is shown in Fig. 6 and compared with the measured impedance. There is a significant difference between the measurement and modeling at low frequencies. Based on reciprocity, the recejve response of the cymbal transducer was calculated from the calculated TVR and impedance using the following equation:

$$
T V R=F F V S+20 \log f-20 \log |Z|+354 .
$$

Fig. 7 shows the calculated FFVS of a cymbal transducer compared with measurement. $A$ difference of about 


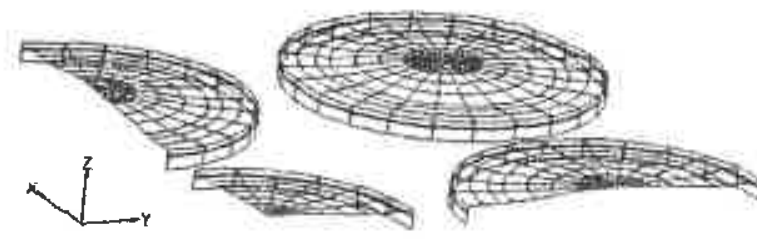

Fig. 8. Meshes of the surface elements of the $3 \times 3$ array. The center cymbal is in the lower left.

$10 \mathrm{~dB}$ exists between the modeling and measurement. To explain the discrepancies, it is necessary to examine the experimental conditions. In the modeling, the electric field was applied directly to the face of the PZT disk, and it does not "sce" the epoxy layer. In the measurement, the lears were comected to the cap instead of the PZT disk for convenience. The insulating epoxy layer sometimes can cause problems because of poor electrical contact. To verify this idea, another cymbal transducer of the same material and cap geometry was assembled with conductive epoxy. The electrical leads were connected to the flange of the cap in the usual way. The measured impedance and FFVS of the modified cymbal are shown in Fig. 6 and Fig. 7, respectively. In both cases, the modeling and measurement agree very well. It is clear now that poor electrical contact between the cap and ceramic is a weak point in the manufacture of a cymbal transducer. This problem can be solved by placing the epoxy layer under compressive stress, which is difficult to achieve experimentally and may complicate the design. Use of conductive epoxy can alleviate the problem by an order of magnitude. Unfortunately, the conductive epoxy usually has lower bonding strength and is not good for high power transmission. This is a materials problem requiring further attention.

\section{B. Array Modeling}

Three symmetry planes cxist for the $3 \times 3$ array; therefore, only one-cighth of the array is modeled. Fig. 8 shows the mesh of the surface elements.

The predicted TVR of a $3 \times 3$ array with a center-tocenter spacing of $15 \mathrm{~mm}$ is shown in Fig. 9 and compared with the measured TVR of the array. In both modeling and measurement, the peaks associated with the resonance have disappeared because of the damping associated with acoustic loading. This is a result of strong acoustin intoraction between adjacent transducers at resonance. Although all the transducers in the array are electrically driven in phase, the amplitude and phase of the vibration of the transducers are very different, depending on their location in the array. The calculated displacement of the dome of transducers in the array is shown in Fig. 10 and compared with that of a single, individual element. At off-resonence frequencies, the displacoment of transducers in the array is pretty much the same as that of a single element. At resonance, the displacement of the center transducer in the array is almost two times larger than that of a single, individual element at this frequency. Because of this

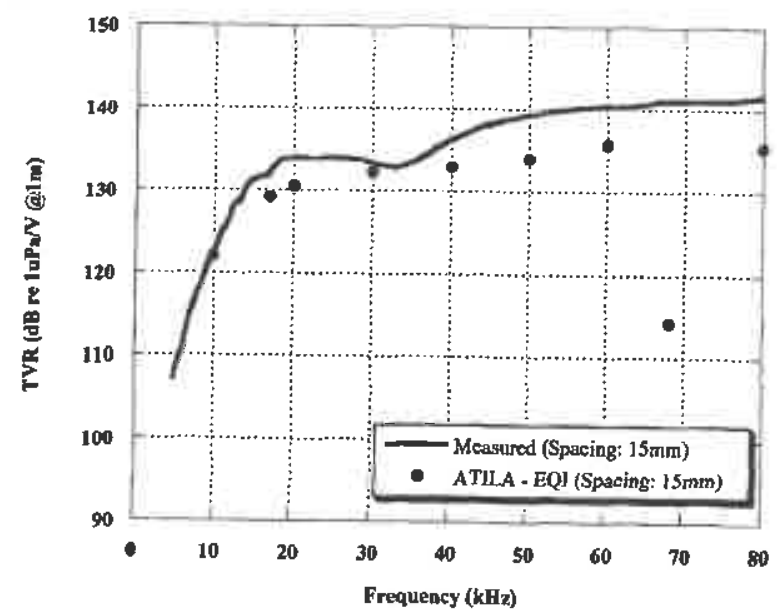

Fig. 9. Predicted TVR of a $3 \times 3$ cymbal array compared with measurement.

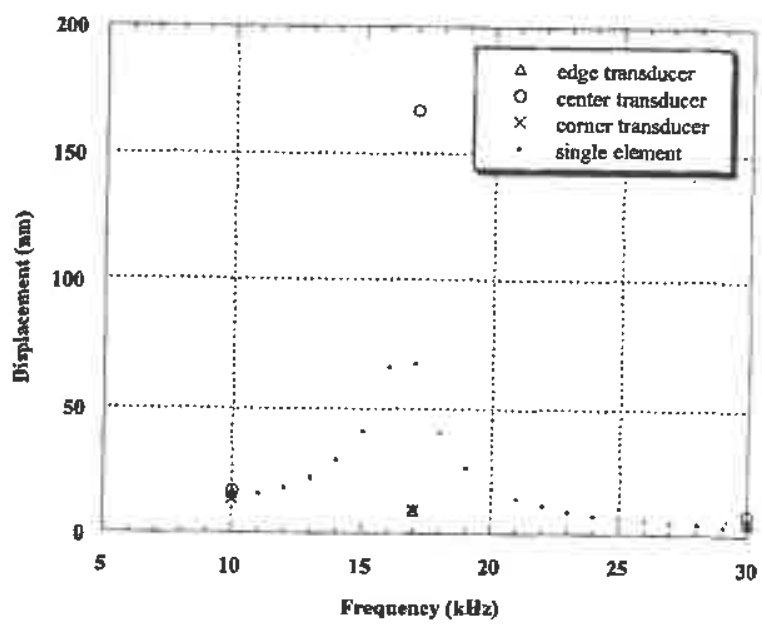

Fig. 10. Calculated displacement of transducers in the array and of a single, individual transducer.

large motion, the stress in the ceramic may exceed the mechanical tolerance and destroy the ceraruic. In addition to mechanical failure, the heat generated in the ceramic due to mechanical and dielectric loss may depole the ceramic, leading to a thermal failure.

Fig. 11 shows the calculated displacement field of transducers in the array at the nominal resonance frequency $(17 \mathrm{kHz})$. The corner transducers actually vibrate out of phase with the other transducers in the array. The pressures from different transducers partially cancel as a result of out of phase vibration. The net effect is, the resulting TVR curves are flattened around its nominal resonance and appear to have a broad band response.

Another consequence of array interaction is the improved efficiency of a $3 \times 3$ cymbal transducer array over 


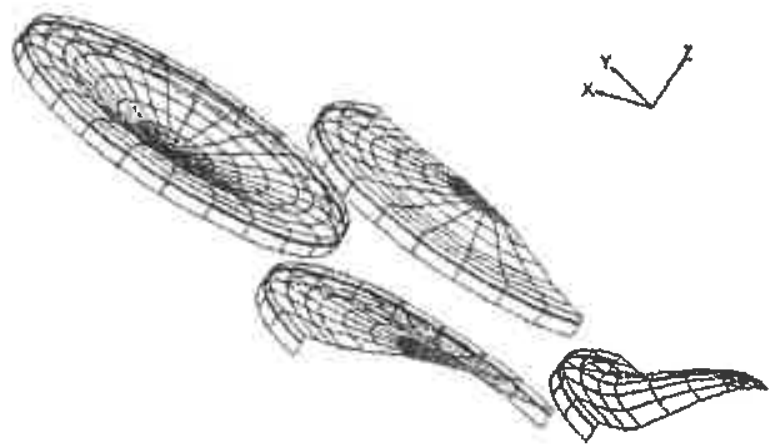

Fig. 11. The displacement fields of the traneducer in the $3 \times 3$ array at $17 \mathrm{kHz}$ (nominal resomance). The center cymbal is in the lower right.

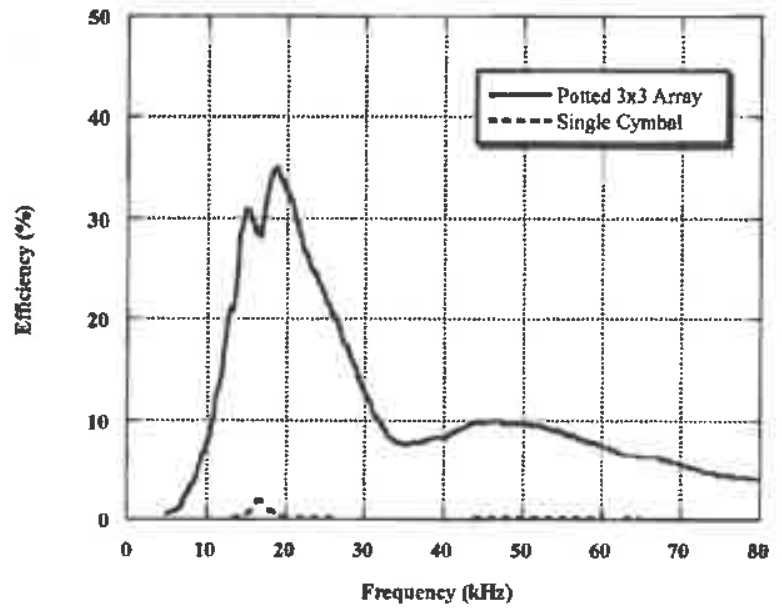

Fig. 12. Mensured eficiency of a single cymbal transducer and of the potted $3 \times 3$ array.

an individual cymbal transducer. This is shown in Fig. 12. The array has an efficiency over $30 \%$ around nominal resonance, compared with the very small efficiency of the single cymbal transducer.

The calculations indicate that array interaction might be disastrous for a closely packed cymbal array driven at the nominal resonance, but there is a way to axoid this problem. Mutual radiation impedance not only depends on element-to-element spacing and operational wavelength, it also depends on the acoustic properties of the transducer surfaces and the shape of the transducer [3]. Instead of having identical transducers in the array, we slightly varied the cavity depth of the transducers in the array so that the surface geometry of the transducers was different. The cavity depth of the center transducer was maintained at $0.32 \mathrm{~mm}$, and the cavity depths for the corner and edge transducers were $0.28 \mathrm{~mm}$ and $0.36 \mathrm{~mm}$, respectively. Fig. 13 shows the calculated displacement of the dome area of the transducers in the array. At nominal resonance the displaccment of the center transducer in the array was greatly damped

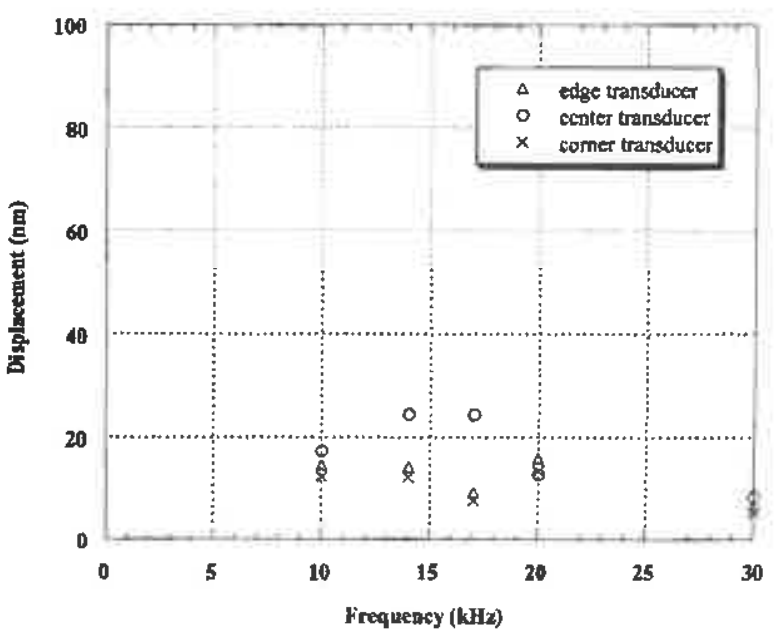

Fig. 13. The reduced motion of transdicers in the array as a regult of varying the surface geometry.

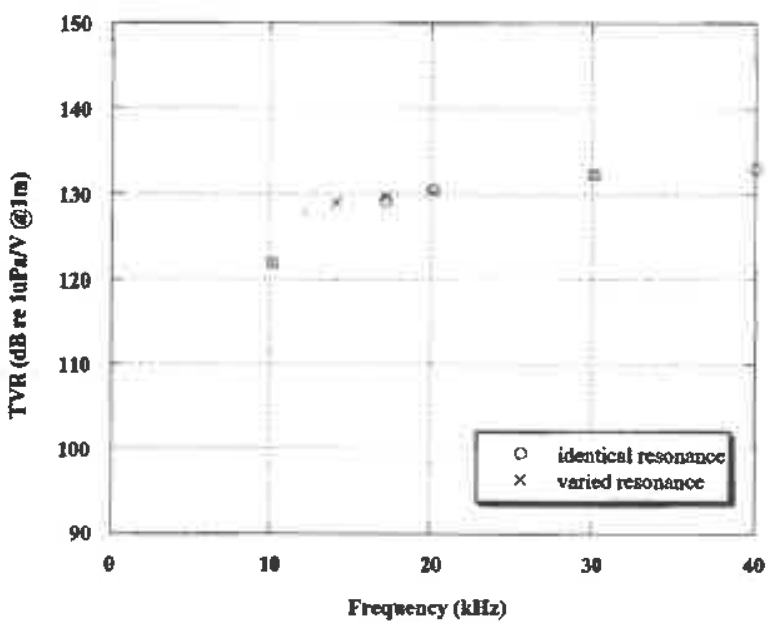

Fig. 14. Predicted TVR of a $3 \times 3$ array of transducers with varied surface geonetry compared with that of a $3 \times 3$ array with identical transducers.

compared with its displacement in an array of identical transducers. It also is much smaller than that of a single, individual cymbal. Therefore, by slightly varying the surface geometry of the transducers in the array, the vibration velocities of the transducers in the array become more uniform, even at resonance, making the array less subject to the aforementioned mechanical and thermal failure. The predicted TVR of this array is nearly identical to the identical-transducer array shown in Fig. 14.

As shown in Fig. 9, the predicted TVR is 2 to $4 \mathrm{~dB}$ lower than the measured walue above the nominal resonance frequency. This discrepancy is believed to be caused by the polymer matrix used in assembling the array. The potted array structure is actually very similar to the popular 1-3 


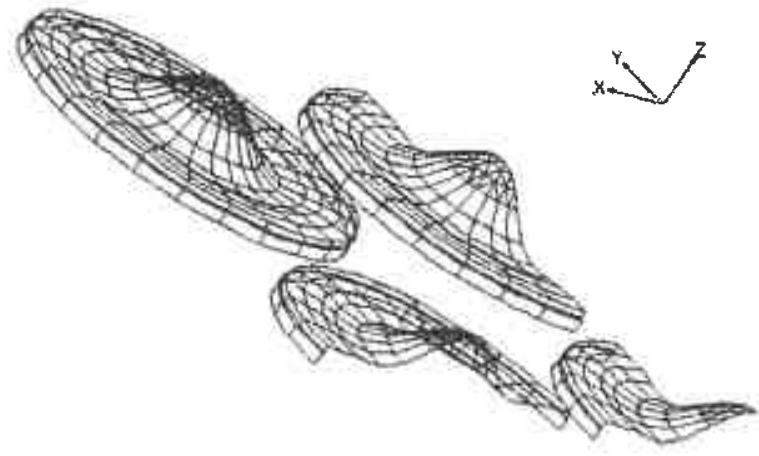

Fig. 15. Displacement field of transducers in the array at $68 \mathrm{kIIz}$.

composite and has a similar decoupling effect [12] caused by the polymer inatrix. As in the 1-3 composite, the radial motion of the ceramic disk is partially suppressed by the polymer matrix, and the axial motion of the caps is not. Therefore, the negative contribution of the radial motion to the sound pressure is reduced. Because the metal caps of the cymbal have an amplified motion in the axial direction, the effective acoustic impedance in the axial direction is reduced, and the polymer may further serve as a matching layer between the cap and water. Therefore, the energy transfer is more efficient in the axial direction than in the lateral direction of the array. The decoupling of the lateral motion of the ceranic from the axial notion asul the improved acoustic matching layer increase the output pressure of the array.

The modeling predicts a sharp dip in the TVR curve for $3 \times 3$ array at $68 \mathrm{kHz}$, as shown in Fig. 9. This corresponds to the sharp dip in the TVR. curve for a single element. The displacement pattern of the array at this frequency is illustrated in Fig. 15. At this frequency all the transducers have a similar vibration mode to that of a single element. Therefore, a dip in the TVR curve at this frequency is experted, but we did not abserve such a dip in the measured TVR. Again, the discrepancy may be ascribed to the polymer matrix that alters the boundary conditions of the transducer elements in the array. Because the mctal capss are in close contact with the polymer matrix, the twonodal point line mode shown in Fig. 15 is not favorable and tends to be suppressed by the polymer matrix. As a result, the TVR is improved in this frequency range.

The vibration mode of transducers in the array at $80 \mathrm{kHz}$ is shown in Fig. 16. The displacernent for each transducer in the array is essentially the same with the same phasc, suggesting little array interaction at this frequency as a result of large spacing to acoustic wavelength ratio at this frequency.

The calculated beam patterns of the $3 \times 3$ array in $\mathrm{XOZ}$ plane at various frequencies are shown in Fig. 17. The acoustic axis is the $\mathrm{OZ}$ direction. At frequencies up to $80 \mathrm{kHz}$, the modeling successfully predicis the main lobes and the side lobes in addition to the nulls in the beam pattern.

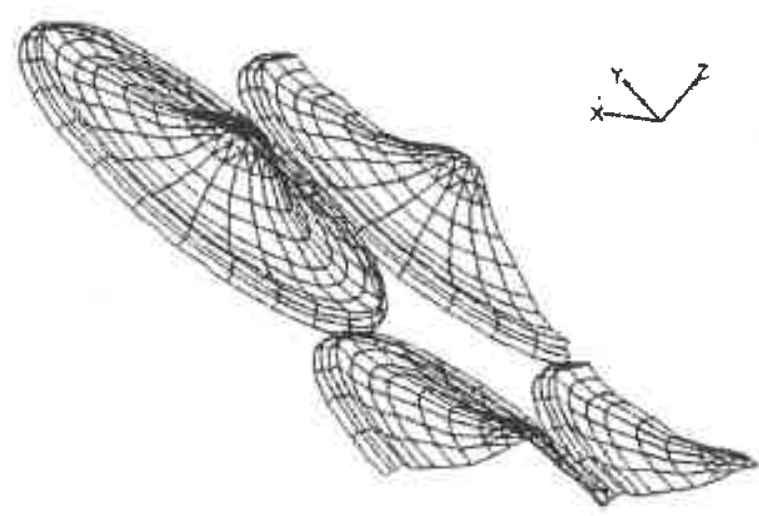

Fig. 16. Displacement field of transducers in the array at $80 \mathrm{kHz}$

The effect of element center-to-center spacing in the array is shown in Fig. 18. At low frequencies when array in teraction is severe, the predicted TVR is very sensitive to the element spacing. At the nominal resonance frequency of $17 \mathrm{kHz}$, the TVR of the array increases from $124 \mathrm{~dB}$ to $133 \mathrm{~dB}$ when the element spacing is increased from $13.5 \mathrm{~mm}$ to $16 \mathrm{~mm}$. The difference is $9 \mathrm{~dB}$ when there is a change in spacing of only $2.5 \mathrm{~mm}$. At higher frequencics, when the wavelength is of the same order of the size of the array $(40 \mathrm{kHz})$, the predicted TVR is less dependent on the spacing.

\section{SUMMARY}

The coupling of finite element analysis and boundary element method provides an efficient way of modeling underwater transducers and arrays. For a single cymbal transducer, excellent agreement was obtained between calculation and measurement using this technique. The thin epoxy layer used to giue the caps to the ceramic disk bas a tremendous effect on the transducer resonance and sensitivity. It is necessary to include the epoxy layer in finite element calculations; even at the cost of fine mesh and long coniputation time.

The acoustic interaction in the array was analyzed using the program EQI. The vibration modes of the transducers in the array behave very differently from a single, individual transducer at low frequencies where acoustic interaction is important. The vibration magnitude and phose of the transducers are strongly affected by the mutual radiation irapedance, which is dependent on surface geometry of the transducors and their locations in the array. As the operational frequency increases, acoustic interaction becomes less severe, and transducers in the array behave more like a single, individual element. In addition to mutual radiation impedance, the vibration of the transducers in the array also is affected by the polymer matrix used in assembling the arruy. The polyner matrix tends to suppress the undesired vibration modes and improve the performance of the array. The combined finite element analysis and in- 


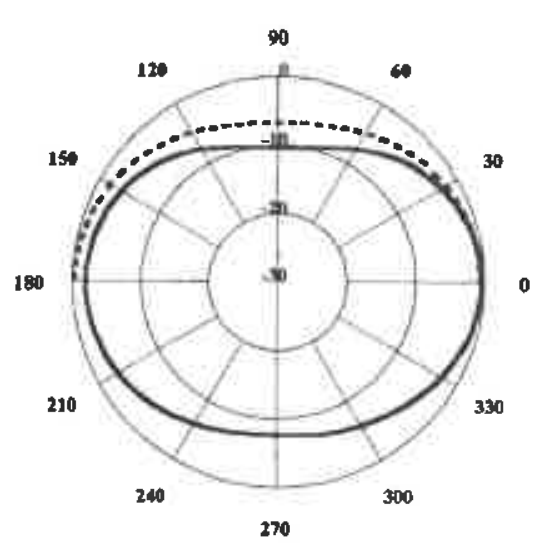

(a)

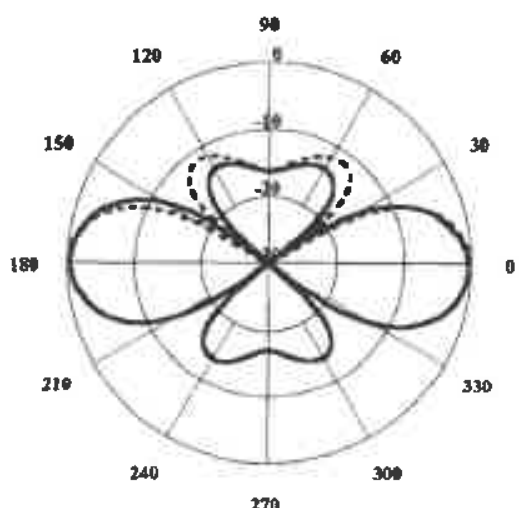

(b)

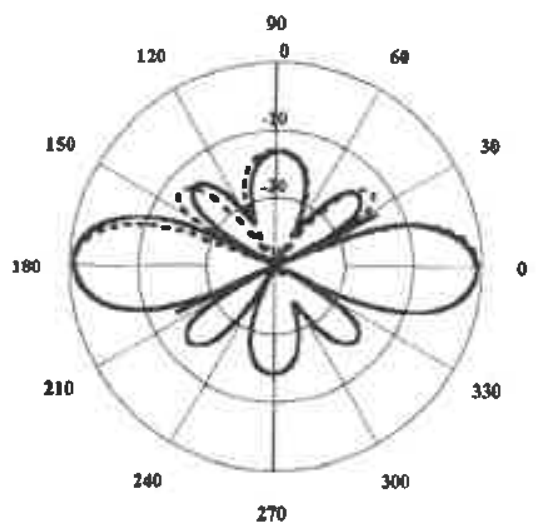

(c)

Fig. 17. Predicted beam patterns of the $3 \times 3$ array compared with the measured beam patterns (a) $20 \mathrm{kHz}_{\text {, }}$ (b) $60 \mathrm{kHw}$, (c) $80 \mathrm{kHz}$ (measured; --- ATILA-EQI).

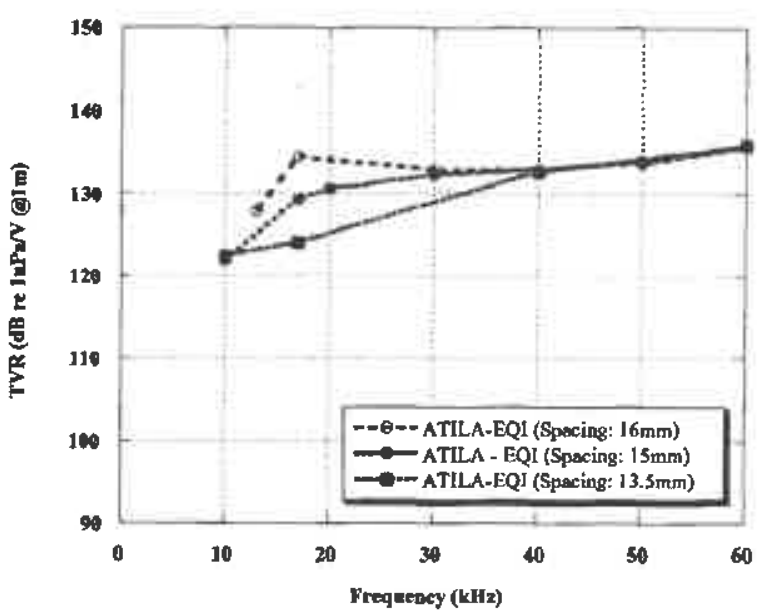

Fig. 18. Effect of element center-to-center spacing on the predicted TVR of a $3 \times 3$ array.

tegral equation method appear to be an effective way of modeling both single clement transduccrs and arrays.

\section{ACKNOWLEDGMENTS}

The authors would like to thank Prof, Kenji Uchino, R. J. Meyer, Jr., Sedat Alkoy and Rattikorn Yimnirun for helpful discussions. Technical services provided by Philippe Bouchilloux of MAGSOFT Co. of New York in using ATILA and EQ1 are also appreciated.

\section{REFERENCES}

[1] A. Dogan, K. Uchino, and R. E. Newnham, "Composite piezo. electric transducers with trunceted conical endcapd 'Cymbals" "IEEF Thans. Ulireson., Ferroelect., Freq. Contr., vol. 44, nо. 3 , pp. $597.605,1997$.

[2] J. F. Tressler, R. E. Newuhan, and W. J. Ifughes, "Capped ceramic underwater sound projector: The 'cymbal' transducer," $J$. Acoust. Soc. Amer., vol. 105 , no. 2, pp. $591-600,1999$.

[3] C. H. Sherman, "Analysis of anoustic interactions in transducer arrays," IEEE Trans. Sonics Ultrason, vol. SL-13, no. 1, pp. $9-15,1966$.

[A] B. F. Hamonic, O. B. Wilson, and J.-N. Decarpigny, "The design of low-frequency underwater acoustic projectors: Present status and future trends, IEEE J. Oceantic Eng., vol. 16, no. 1, pp. and future tre

[5] SWANSON Analysis Systems, Inc., ANSYS User's Manual, Revision 5. Houston, PA. SWANSON Analysis Systems, Inc., 1992.

[6] N. N. Abbroud, G. L. Wojcik, D. K. Vaughan, J. Mould, D. J. Powell, and L. Nikodym, "Finite element modeling for ultrasonic transducers ${ }^{h}$ in Proc. /nt. Symp. Med. Imaging, 1998, pp. 19 42.

[7] MAGSOFT Corporation, ATILA Veraion 5.1X Vser's Manual Troy, NY: MAGSOFT Corp., 1997.

[8] B. Hamonic, J. C. Debus, J.-N. Decarpiguy, D. Boucher, and B. Tocquet, "Analysis of a radiating thir-shell sonar traneducer using the finite element method," $J$. Acoust. Soc. Amer, vol. 86 , no. 4, pp. $1245-1253,1989$.

[9] B. Stupfe], B. Lavie, and J.-N. Decarpigny, "Combined integral equarion formulation and null-field nnethod for the exterior acoustic problem," J. Acoust. Soc. Amer., vol. 83, no. 3, pp.
927 - 941 , 1988 . 
[10] ISEN, EQt User's Manwal france: ISEN, 1999

11 J. Zhang, W. J. IIughes, R. J. Meyer, Jr., K. Uchino, and R. E. Newnham, "Cymbal array; $A$ broad band sound projector ${ }^{n}$ Ut trastonics, vol. 37, pp. 523-529, 2000.

[12] K. A. Klicker, J. V. Biggers, and H. E. Newnham, "Composites of PZT and epoxy for hydrostatic transducer applications" Amer: Cerom. Soc., vol. 64, no. 1 , pp. 5-4, 1981 .

Jindong Zhang was born in Nanyang, China on February 1, 1970. He received the B.S. degree in ceramic science and entineering in 1991 from Zhejiang University in Ching, and the M.S. degree in in ramic engineering in 1996 from Shanghai Institute of Ceramics, Chinese Acaderny of Scjences. He worked in Dalian Porcelain Inet ChiWorks, Chint, as an engineer from 1991-1993.

He curnintly is a Ph.D. student in Intercollege Programe in Ma terials and The Pennsylvania State University, University Park, PA. His research interests are in electroceramics, piezoclectrjc actuators,

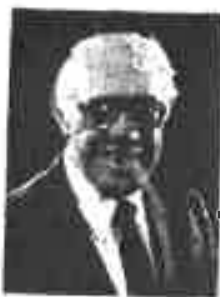

Rohert E. Newnham (M'85) was born in Ansterdam, NY, on March 28,1929 . He re ceived the B.S. degree in mathematics in 1950 from Hartwick College, Oneonta, NY the M.S. degree in physics from the Colorado State University, Fort Collins, CO; a Ph.D. Penusylvania State Uriversilyz, as doctorate in crystallography University in 1960 .

He Is ALCOA professor of solid state sciterials Pesearch ence and former Absociate Director of the Ma terials Research Lab at The Pennsylvania Stale University, Univerdity Park, PA. His research interests are in tions, electroceramics, and corerests are in structure-property relacations. 